\title{
Sensitivity of panoramic radiographs in diagnosing maxillary sinusitis: a scoping review
}

\author{
Vera Widyastuti ${ }^{*}$, Azhari $^{2}$, Lusi Epsilawati² ${ }^{\text {iD }}$
}

\begin{abstract}
Objectives: The purpose of this study was to articles published in 2010-2020. determine the sensitivity of using this panoramic radiograph in diagnosing maxillary sinusitis.

Review: Scoping Review with article searches was carried out through NCBI's PubMed database, Science Direct, and EbscoHost from January 2020 to March 2021, with the inclusion criteria being

Conclusion: Panoramic radiographs were found to be less sensitive for diagnosing maxillary sinusitis, but due to the low availability and accessibility of CBCT and $\mathrm{CT}$, and related to their expensive cost and high radiation, panoramic radiographs are considered to be quite optimal.

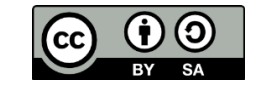

This work is licensed under a
Creative Commons Attribution 4.0 Creativiv Commons Attribution 4.0 phrovided that the original work is properly cited,
pition actaptations are made.
and nom

Keywords: Maxillary sinusitis, panoramic radiography

Cite this article: Widyastuti V, Azhari, Epsilawati L. Sensitivity of panoramic radiographs in diagnosing maxillary sinusitis: a scoping review. Jurnal Radiologi Dentomaksilofasial Indonesia 2021;5(3)136-41. https://doi.org/10.32793/ jrdi.v5i3.703
\end{abstract}

${ }^{1}$ Faculty of Dentistry, Universitas Padjadjaran, Bandung, Indonesia 40132

${ }^{2}$ Department of Dentomaxillofacial Radiology, Faculty of Dentistry, Universitas Padjadjaran, Bandung, Indonesia 40132

${ }^{*}$ Correspondence to:

Vera Widyastuti

冈vera17004@mail.unpad.ac.id

Received on: August 2021

Revised on: September 2021

Accepted on: October 2021

\section{INTRODUCTION}

Maxillary sinusitis is inflammation of maxillary sinus which can be classified as choric sinusitis when the inflammation persists for more than 12 weeks. Sinusitis is considered as the main cause of rinogen. However, in several cases, the fact shows that dental infection is the main predisposition factor. ${ }^{1}$ Primarily, unilateral maxillary sinusitis cases have an odontogenic origin caused by periapical lesions and upper jaw teeth removal. Changes in the maxillary sinuses have been reported in $71.3 \%$ of patients with dental infections. ${ }^{2}$

Panoramic radiograph becomes widely used for diagnosis aids for dental treatment planning and can be used as an early indication. Moreover, in some cases, it can positively provide a moderately clear picture, especially in the molar region of the lower jaw. Sinus region can be shown in the anterior posterior sinus wall, sinus roof and Maxillary sinus base. The basic image of the sinuses often experiences superimpose with the nearest bones especially the durum palate and zigoma. As a result, in many cases, the sinus basic pathology is not observable, especially when it merely involves the change in the sinus basic soft tissue. ${ }^{3}$

Panoramic radiograph, known as Orthotopantomography (OPG), is widely used in dental and facial pain examinations. Radiographic modality shows jawbone, teeth, and supporting structures including temporomandibular joints and maxillary sinuses, all of which can be the cause of facial pain. ${ }^{4}$ Some of the advantages that panoramic radiography may offer are relatively low radiation dose, ${ }^{5}$ wide availability and relatively inexpensive cost. Moreover, it provides a great variety of information for dentists, not only in detecting caries and periodontal disease but also in detecting jaw tumors, temporomandibular joint arthritis and systemic diseases such as osteoporosis. In addition, it shares accurate information in medical diagnoses such as the presence of a globular radiopaque mass on the posterior wall or floor. ${ }^{6}$ On the other hand, it has several disadvantages in detecting defects in the posterior wall ${ }^{7}$ resulting from the artifact or superimposition caused by hard palate (palatum durum) and inferior nasal concha. Thus, diagnosing a disease affecting the maxillary sinus frequently requires great efforts, especially for inexperienced clinicians. $^{2}$

The purpose of this study is to determine the panoramic radiographs accuracy in diagnosing maxillary sinus. The research was carried out by collecting a number of articles from the PubMed NCBI, EBSCOhost and Science Direct databases which were adjusted to the predetermined keywords and then synthesized to meet the research questions.

\section{REVIEW}

This article was written using scoping review approach. This is an initial assessment of the potential size and scope of available research literature which aims to identify the nature and 
level of research evidence. ${ }^{8}$ Tools and materials used in the study were stationery, laptop, and the Microsoft Words software. The databases used in this study were PubMed NCBI, Science Direct, and EbscoHost. The articles search method uses "Boolean Operators" using "(Maxillary Sinusitis) AND (Disorders) AND (Panoramic Radiograph)" as the keywords.

The articles used are the ones published between 2010-2020 from the NCBI PubMed database, Science Direct, and EbscoHost as the reference point of the study. The aim of study was to determine the accuracy of panoramic radiographs in diagnosing maxillary sinusitis. The eligibility criteria are compiled based on the Research Question, which is compiled through the PICO format used to clearly and comprehensibly define clinical question. PICO format itself is the acronym of Population or Problem, Intervention or Exposure, Comparison, and Outcome. ${ }^{9}$ The articles were searched using Advanced Search with Boolean Operators "AND" and "OR" on the database using keywords predetermined and adjusted to the inclusion and exclusion criteria. In addition, manual search was conducted to complete the search. The research was conducted online from January 2020 to March 2021.

The articles were searched using Advanced Search with Boolean Operators "AND" and "OR" on the database using keywords predetermined and adjusted to the inclusion and exclusion criteria. In addition, manual search was conducted to complete the search. The research was conducted online from January 2020 to March $2021 .{ }^{10}$ Selected articles will be methodically screened for three times; (i) articles are screened by examining the possible duplication of each article on the database, (ii) ) articles are critically reviewed by selecting the title and abstract, and those that do not meet the inclusion criteria and research objectives are then screened, and (iii) articles are reviewed by reading their entire contents and screening according to the exclusion criteria. After that, the selected articles are synthesized qualitatively (Scoping Review).

The data of selected articles will be extracted with the collected data consisting of author's name, year of publication, article title, research method, number and type of participants, age, radiographic technique, results, and conclusions. The data will be tabulated and analyzed using the thematic analysis principle, a method used in identifying themes or problems from various studies, analyzing, interpreting, explaining, and taking into conclusions in a systematic review. ${ }^{11}$

After the selection using predetermined search engine was done, the search results by using predetermined keywords were 1,122 articles, consisting of 68 articles from Pubmed NCBI, 735 articles from Science Direct, and 319 articles from

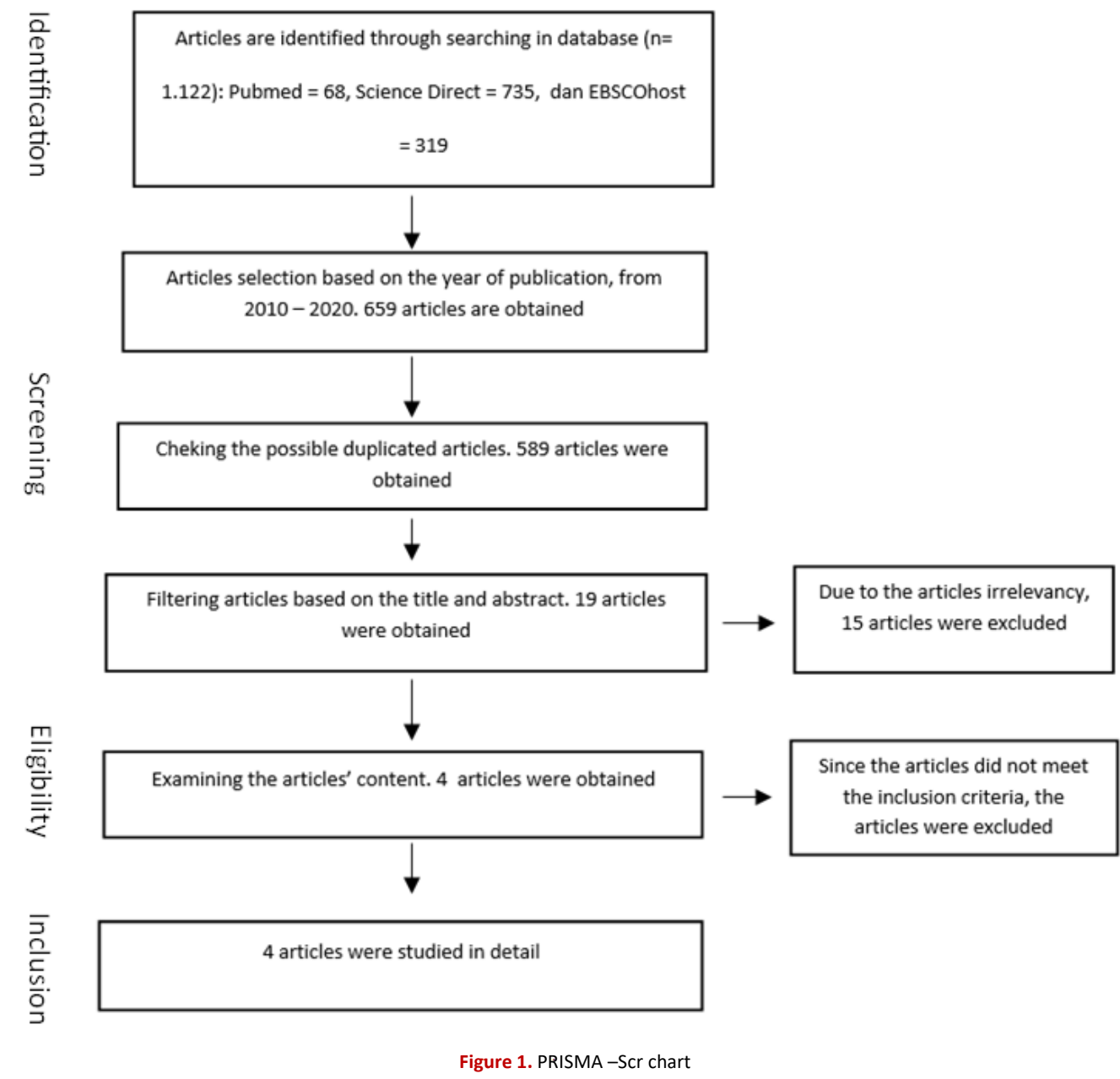


Ebsco Host. The number of articles obtained by year of publication between 2010-2020 was 659 articles. In the second screening, where the duplicated articles were excluded, 589 articles were obtained. In the third screening, where the articles were selected based on the title and abstract, 19 articles were obtained. Furthermore, after examining the entire article contents, 4 articles were obtained which would be used as the research samples. The article search process is shown in Figure 1.

Articles included in inclusion criteria are shown in Table 1. The characteristics of articles included in inclusion criteria are shown in Table 2 . There are four articles to be studied in detail along with a variety of sinus cases and to use panoramic techniques with maxillary sinus cases using reference standards.

The research results from each article are shown in Table 1. Different results are shown by each article. The first articles examined using periapical radiography, panoramic radiography, and CT (Computed Tomography), showed that the CT sensitivity is $89.7 \%$ and specificity is $94.6 \%$, panoramic radiography has sensitivity of $68.2 \%$ and specificity $77.3 \%$, Periapical Radiography Sensitivity $77.9 \%$ and Specificity $67 \%{ }^{16}$ The second articles examined using $\mathrm{CT}$ or $\mathrm{CBCT}$ techniques and Panoramic Radiography showed that the panoramic radiographic technique is high, with accuracy $87.5 \%$, sensitivity $86.7 \%$, specificity $88.3 \%{ }^{14}$ The third article examined using the CBCT technique and panoramic radiography showed that $\mathrm{CBCT}$ results showed a firm connection between the first and second molars with the maxillary sinus, respectively, in $54 \%$ and $38 \%$, while the panoramic radiograph identifies two. ${ }^{13}$ Furthermore, the fourth article examined using acetate conventional panoramic radiography and CT techniques showed that panoramic radiographs provide an accurate diagnosis which reaches $70 \%$ of cases time whereas conventional CT in acetate provides a highly accurate diagnosis to $89.9 \%$ of cases. ${ }^{16}$

\section{DISCUSSION}

Maxillary sinusitis of odontogenic origin is the cause of one-tenth of all cases of maxillary sinusitis. The proximity of the maxillary sinus to the upper posterior teeth give raise to dental disease to be a potential source of maxillary sinusitis. ${ }^{16}$ Maxillary sinusitis is often caused by apical and/or periodontal lesions of the maxillary molars. ${ }^{14}$

Knowledge of the anatomic and pathological relationships between the maxillary posterior teeth or the edentulous area and the maxillary sinus is necessary for diagnosis and treatment planning. Although the maxillary sinusitis diagnosis is predominately based on clinical signs, radiological findings are practicable in identifying the fundamental etiologic factor. Determining maxillary sinusitis etiology has important implications for clinical management since the pathophysiology, microbiology, and treatment of odontogenic maxillary sinusitis differs from rhinogenic sinusitis. The closer the roots of the maxillary posterior teeth to the base of the maxillary sinus, the greater the risk of a mucosal reaction in tooth-related pathologies. Whereas mucosal thickening in the maxillary sinus implies irritation. The irritation may be odontogenic in nature when unilateral and focal changes exist in the sinus floor mucosa focal around the tip of the root or extracted tooth. ${ }^{13}$

The relationship between the maxillary posterior teeth and the maxillary sinus can be assessed using various radiographic techniques. ${ }^{13}$ Radiographic imaging has a great significant role in establishing the odontogenic etiology of maxillary sinusitis and completing the clinical findings. ${ }^{16}$

Panoramic radiography is one of the leading radiographic techniques in oral health care. ${ }^{13}$ Panoramic radiography also reduces the representation of the arch surface and provides a clear view of the sinus floor area and its relationship to the maxillary teeth. It makes determining the size of the periapical lesions, cysts and mucosal thickening in the maxillary sinus possible. ${ }^{16}$

Table 1. Articles included in inclusion criteria

\begin{tabular}{|c|c|c|c|}
\hline Author & Year & Study Design & Title \\
\hline Simuntis, et al. ${ }^{12}$ & 2017 & $\begin{array}{l}\text { Observational } \\
\text { Study }\end{array}$ & $\begin{array}{l}\text { Clinical efficacy of main radiological diagnostic } \\
\text { methods for odontogenic maxillary sinusitis }\end{array}$ \\
\hline Murata, et al. ${ }^{14}$ & 2019 & $\begin{array}{l}\text { Retrospective } \\
\text { Study }\end{array}$ & $\begin{array}{l}\text { Deep-learning classification using convolutional } \\
\text { neural network for evaluation of maxillary } \\
\text { sinusitis on panoramic radiography }\end{array}$ \\
\hline Shahbazian, et al. ${ }^{13}$ & 2014 & $\begin{array}{c}\text { Comparative } \\
\text { Study }\end{array}$ & $\begin{array}{l}\text { Comparative assessment of panoramic } \\
\text { radiography and CBCT imaging for } \\
\text { radiodiagnostics in the posterior maxilla }\end{array}$ \\
\hline $\begin{array}{l}\text { Maestre-Ferrín, et } \\
\text { al. }^{16}\end{array}$ & 2011 & $\begin{array}{c}\text { Comparative } \\
\text { Study }\end{array}$ & $\begin{array}{l}\text { Radiographic Findings in the Maxillary Sinus: } \\
\text { Comparison of Panoramic Radiography with } \\
\text { Computed Tomography }\end{array}$ \\
\hline
\end{tabular}




\begin{tabular}{|c|c|c|c|c|}
\hline Author, Year & Year & Technique & Result & Conclusion \\
\hline $\begin{array}{l}\text { Simuntis, et } \\
\text { al. }(2017)^{12}\end{array}$ & 3 months & $\begin{array}{l}\text { Periapical radiography, } \\
\text { panoramic radiography, } \\
\text { and } \mathrm{CT} \text { (Computed } \\
\text { Tomography) }\end{array}$ & $\begin{array}{l}\text { Results agreed by } \\
\text { observers: } \\
\text { 1) CT Sensitivity } 89.7 \\
\text { and Specificity } 94.6 \% \text {, } \\
\text { 2) Panoramic } \\
\text { Radiography } \\
\text { Sensitivity } 68.2 \text { and } \\
\text { Specificity } 77.3 \% \text {, } \\
\text { 3) Periapical } \\
\text { Radiography } \\
\text { Sensitivity } 77.9 \text { and } \\
\text { Specificity } 67 \%\end{array}$ & $\begin{array}{l}\text { In diagnosing maxillary } \\
\text { sinusitis using Computed } \\
\text { Tomography, Panoramic } \\
\text { radiography is less in accuracy }\end{array}$ \\
\hline $\begin{array}{l}\text { Murata, et al. } \\
(2019)^{14}\end{array}$ & 3 months & $\begin{array}{l}\mathrm{CT} \text { or } \mathrm{CBCT} \text { and } \\
\text { panoramic radiography }\end{array}$ & $\begin{array}{l}\text { Performance of } \\
\text { diagnostic system of } \\
\text { deep learning for } \\
\text { maxillary sinusitis } \\
\text { Panoramic radiography is } \\
\text { classified as high, with an } \\
\text { accuracy of } 87.5 \% \text {, } \\
\text { sensitivity } 86.7 \% \text {, } \\
\text { specificity } 88.3 \%\end{array}$ & $\begin{array}{l}\text { The diagnostic performance } \\
\text { for maxillary sinusitis on } \\
\text { panoramic radiographs is } \\
\text { quite high }\end{array}$ \\
\hline $\begin{array}{l}\text { Shahbazian, } \\
\text { et al. }(2014)^{13}\end{array}$ & 8 months & $\begin{array}{l}\mathrm{CBCT} \text { and panoramic } \\
\text { radiography }\end{array}$ & $\begin{array}{l}\text { The close connectedness } \\
\text { of the first and second } \\
\text { molars with the maxillary } \\
\text { sinus was, respectively, in } \\
54 \text { and } 38 \% \text {. } \\
\text { Thirty-nine apical } \\
\text { periodontitis lesions } \\
\text { causing reactive changes } \\
\text { in the maxillary sinus } \\
\text { were detected by CBCT, } \\
\text { while six of them were } \\
\text { diagnosed using } \\
\text { panoramic radiography. }\end{array}$ & $\begin{array}{l}\text { Panoramic radiography in the } \\
\text { radioanatomical and } \\
\text { radiodiagnostic observation of } \\
\text { the maxillary posterior } \\
\text { visualization of maxillary sinus } \\
\text { inclusion posterior maxillary } \\
\text { teeth }\end{array}$ \\
\hline $\begin{array}{l}\text { Maestre- } \\
\text { Ferrín, et al. } \\
(2011)^{16}\end{array}$ & - & $\begin{array}{l}\text { Panoramic radiography } \\
\text { and conventional CT } \\
\text { acetate }\end{array}$ & $\begin{array}{l}\text { 1. Results of the right } \\
\text { sinus } \\
\text { Panoramic radiographs } \\
\text { showed } 70 \% \text { of a correct } \\
\text { diagnosis }\end{array}$ & $\begin{array}{l}\text { Computed tomography is the } \\
\text { leading method in recent days } \\
\text { in diagnosing maxillary sinus } \\
\text { pathology compared to } \\
\text { panoramic radiograph }\end{array}$ \\
\hline & & & $\begin{array}{l}\text { 2. Results of the left sinus } \\
\text { Panoramic radiographs } \\
56.7 \%\end{array}$ & \\
\hline
\end{tabular}

Although panoramic radiography makes a wider coverage of facial bones and teeth with a relatively low radiation dose possible, it shows disadvantages such us distortion and blurred image. ${ }^{13}$ It is important to notice that panoramic radiography has lower sensitivity than periapical radiography in detecting apical periodontitis. Furthermore, this technique has disadvantage in the upper molar region due to its 2D nature and anatomical superimposition. ${ }^{16}$

For other imaging, the $3 \mathrm{D}$ imaging from Computed Tomography (CT) or Cone Beam Computed Tomography (CBCT), for example, can overcome the panoramic radiography disadvantages by providing a multiplanar view of the maxillofacial region. CT is still considered as the gold standard in imaging sinonasal lesions, which produces higher radiation doses. Nowadays, CT has drastically dropped in the radiation dose without losing the image quality. However, its accessibility and applicability are limited in diagnosing the oral health care.$^{13} \mathrm{CT}$ has several advantages compared to the conventional radiography such as eliminating the superimposition of anatomical structures outside the area of interest and having high resolution and high contrast, making it possible to distinguish differences between different tissues in physical density less than $1 \%$, compared to $10 \%$ for conventional radiographs. ${ }^{15}$

It is noted that this modality is impractical in a dental application due to its relatively high radiation dose and relatively low spatial resolution. Even though several studies have tried to use the low-dose CT examination on the paranasal sinuses by decreasing the tube flow, their use is limited to cases of odontogenic sinusitis since the details associated with specific pathologies of the teeth and bones may need more clarity. Another disadvantage of $\mathrm{CT}$ is related to metal artifacts since metal objects around the teeth can make the image 
analysis hard. ${ }^{15}$

In contrast to $\mathrm{CT}, \mathrm{CBCT}$ produces high-resolution isotropic volume data at a lower dose and cost. At the same time the visualization quality of the maxillary sinus and bone structure is conforming in every respect. Therefore, CBCT is able to facilitate the diagnosis of specialized teeth in oral health care. ${ }^{13}$ Cone Beam Computed Tomography, which has a cone beam computed tomography, is a relatively new diagnostic imaging modality. It has been used in a variety of applications in dentistry. It is suitable to be recommended as a dose-saving technique compared to the alternative medical CT scanning for common oral and maxillofacial radiographic imaging tasks. This modality shows high spatial resolution and high accuracy in finding apical periodontitis and mucosal thickening compared to 2D imaging, especially in maxillary teeth. The presence of metal artifacts is another disadvantage of CBCT. However, this issue was overcome by producer artifact suppression algorithm and an increased number of projections. ${ }^{15}$

In a study conducted by Maillet et al., $55 \%$ first molars cases and $34 \%$ apical periodontitis of second molars case were the cause of Odontogenic Maxillary Sinusitis. In recent days, the periapical pathology diagnosis is mostly based on panoramic radiographic examination. According to the literature, the sensitivity in identifying periodontitis is about $60 \%$ for panoramic radiographs. The main disadvantages of this imaging are the overlapping of the maxillary triple-rooted molars and the superimposition of anatomical structures, such as the zygomatic process. In addition, the ability to detect apical lesions radiographically depends on the involvement of cortical bone and X-ray angulation. Thus, part of the apical periodontal lesion is unobservable. According to Petersson et al. meta-analysis, panoramic radiography sensitivity and specificity are respectively $98 \%$ and $100 \%$. According to Simuntis et al., the overall sensitivity of panoramic radiographs was $66 \%$ higher and specificity $67 \%$ lower. Results may be different in some particular way since, as shown in the studies, the accuracy of the radiological method depends on the specialist's interpretation of the radiological imaging modality. ${ }^{16}$

A the conclusion of several expert opinions, it indicates that $\mathrm{CT}$ is most specific method with the best accuracy when this view is evaluated by an experienced oral radiologist. However, in clinical practice, patients is permitted to be scanned in hospital only. More importantly, images are viewable for an experienced oral radiologist at any given time. The increasing popularity and use of $\mathrm{CBCT}$ in dental practice makes diagnosis posing no difficulty. ${ }^{16}$

Sakakura et al. showed that the majority of dentists prescribe panoramic radiographs. Moreover he found that more than $95 \%$ of dentists obtain panoramic radiographs in at least $80 \%$ of their patients. In another study, Charles et al. assessing respondents' awareness on the use of Cone Beam Computed Temography (CBCT) diagnostic application. As a result, $48.3 \%$ of respondents were unaware of $\mathrm{CBCT}$ and $82 \%$ of dentists considered $\mathrm{CBCT}$ too expensive or inconvenient to be used by their patients.

This research has shortcomings in some aspects such as the lack of articles that explain the effectiveness of panoramic radiographs in diagnosing maxillary sinusitis disorders in the past 10 years. Furthermore, the review process is only carried out by one person which might lead to a potential subjectivity in the review result.

\section{CONCLUSION}

Although the panoramic radiograph is less sensitive, it has a great significance to know and to learn more about the sinusitis images. Due to the fact that it is widely used by dentist, panoramic radiographs can be optimized. Although $\mathrm{CBCT}$ and CT are far more sensitive, their use is still low due to their limited availability, high price, and high radiation levels. Keeping the effort in diagnosing maxillary sinusitis with more number of articles, more number of samples, and wider research variables for more accurate results is required.

\section{ACKNOWLEDGMENTS}

None.

\section{FOOTNOTES}

All authors have no potential conflict of interest to declare for this article.

\section{REFERENCES}

1. Fabre C, Atallah I, Wroblewski I, Righini CA. Maxillary sinusitis complicated by stroke. Eur Ann Otorhinolaryngol Head Neck Dis. 2018;135(6):449-51.

2. Aukštakalnis $R$, Simonavičiūtè $R$, Simuntis $R$. Treatment options for odontogenic maxillary sinusitis: a review. Stomatologija. 2018;20(1):22-6

3. Sun W, Xia K, Tang L, Liu C, Zou L, Liu J. Accuracy of panoramic radiography in diagnosing maxillary sinus-root relationship: $A$ systematic review and meta-analysis. Angle Orthod. 2018;88 (6):819-29.

4. Constantine S, Clark B, Kiermeier A, Anderson PP. Panoramic radiography is of limited value in the evaluation of maxillary sinus disease. Oral Surg Oral Med Oral Pathol Oral Radiol. 2019;127(3):237-46

5. Suomalainen A, Pakbaznejad Esmaeili E, Robinson S. Dentomaxillofacial imaging with panoramic views and cone beam CT. Insights Imaging. 2015;6(1):1-16.

6. Ohba $T$, Ogawa $Y$, Hiromatsu $T$, Shinohara $Y$. Experimental comparison of radiographic techniques in the detection of maxillary sinus disease. Dentomaxillofac Radiol. 1990;19 (1):13-7.

7. Ohba T, Ogawa Y, Shinohara Y, Hiromatsu T, Uchida A, Toyoda $Y$. Limitations of panoramic radiography in the detection of bone defects in the posterior wall of the maxillary sinus: an experimental study. Dentomaxillofac Radiol. 1994;23(3):149 53.

8. Tricco AC, Lillie E, Zarin W, et al. PRISMA Extension for Scoping Reviews (PRISMA-ScR): Checklist and Explanation Ann Intern Med. 2018;169(7):467-73.

9. Using PICO or PICo - Systematic Reviews - Research Guide Help and Support at Murdoch University. https:// 
libguides.murdoch.edu.au/systematic/PICO

10. Liberati A, Altman DG, Tetzlaff J, et al. The PRISMA statement for reporting systematic reviews and meta-analyses of studies that evaluate healthcare interventions: explanation and elaboration. BMJ. 2009;339.

11. Cruzes DS, Dyba T. Recommended Steps for Thematic Synthesis in Software Engineering. In: International Symposium on Empirical Software Engineering and Measurement. IEEE Computer Society. 2011;275-84.

12. Simuntis $R$, Kubilius $R$, Padervinskis $E$, Ryškienè $S$, Tušas $P$, Vaitkus $S$. Clinical efficacy of main radiological diagnostic methods for odontogenic maxillary sinusitis. Eur Arch OtoRhino-Laryngology. 2017;274(10):3651-8.

13. Shahbazian M, Vandewoude C, Wyatt J, Jacobs R. Comparative assessment of panoramic radiography and CBCT imaging for radiodiagnostics in the posterior maxilla. Clin Oral Investig. 2014;18(1):293-300.

14. Murata $\mathrm{M}$, Ariji $\mathrm{Y}$, Ohashi $\mathrm{Y}$, et al. Deep-learning classification using convolutional neural network for evaluation of maxillary sinusitis on panoramic radiography. Oral Radiol. 2019;35(3):301-7.

15. Shahbazian $M$, Jacobs $R$. Diagnostic value of $2 D$ and $3 D$ imaging in odontogenic maxillary sinusitis: A review of literature. J Oral Rehabil. 2012;39(4):294-300.

16. Maestre-Ferrín L, Galán-Gil S, Carrillo-García C, PeñarrochaDiago M. Radiographic findings in the maxillary sinus: comparison of panoramic radiography with computed tomography. Int J Oral Maxillofac Implants. 2011;26(2):341-6. 